\title{
ARQUEOLOGÍAS DE LA IMAGEN-RED. LA SUBJETIVIDAD DIALÓGICA EN LEVEL FIVE DE CHRIS MARKER
}

Archeology of the image-network. Dialogic subjectivity in Chris Marker's Level Five

David Montero Sánchez*

\section{Resumen}

El presente artículo explora la presencia de un principio dialógico en la configuración de las subjetividades que interactúan en Level Five de Chris Marker con el objetivo de matizar la metáfora crítica que califica de forma consistente el cine del director francés como ejemplo del autorretrato. Mediante el concepto bajtiniano de "devenir ideológico", el texto presta especial atención a la creciente importancia que juegan las tecnologías de la comunicación en los procesos de reacentuación discursiva que determinan en último término la construcción de subjetividades. La noción de "imagen-red" busca poner de relieve las formas en las que la imagen digital ha propiciado el desarrollo de un nuevo pasaje de la imagen hacia un régimen representativo dominado por las ideas de intercambio autoinscripción cuyos ecos Level Five explora mediante el análisis de aspectos que van desde la dicotomía entre historia y memoria al papel de la imagen documental en la construcción de la realidad.

Palabras clave: Chris Marker. Dialogismo. Reacentuación. Documental. Devenir ideológico.

\section{Abstract}

This article analyzes the presence of a dialogic principle in the way subjectivities are constructed within Chris Marker's Level Five, with a view to critically counteract the notion of Marker's films as forms of the self-portrait. Through the Bakhtinian concept of "ideological becoming", special attention is paid to the role played by new technologies of information and communication in the processes of re- accentuation which determine how subjectivities evolve in the context of the film. The concept of an "image-network" attempts to highlight the development of a new passage of the image towards a mode of representation dominated by a principle of exchange, whose importance is echoed in the film through the analysis of issues ranging from the dichotomy between memory and history to the relevance of documentary image for reality construction.

Key words: Chris Marker. Dialogism. Re-accentuation. Documentary. Ideological becoming.

\section{INTRODUCCIÓN}

En unas notas de 1984 publicadas en su libro Entre Imágenes, Raymond Bellour repasa las formas en que los modos expresivos del video habían ido desplazando al cine hacia el terreno de la literatura, en general, y hacia el género de la autobiografía de forma más concreta. El crítico francés aún afinaba algo más cuando explicaba que el video había extendido entre los cineastas la fórmula del autorretrato. Frente a la estructura narrativa de la autobiografia, el cine comenzaba a acercarse al autorretrato 
como espacio poético menos articulado, que convoca un sentido vago pero sólido de lo íntimo. Para Bellour, el autorretrato cinematográfico gira "alrededor de la pregunta incesantemente repetida: “¿quién soy?” (Entre imágenes, 286). Se trata de un monólogo continuo, en el que si bien el sujeto busca situar su experiencia personal en marcos interpretativos generales (lo que, por ejemplo, ha dotado al autorretrato filmico de un marcado carácter autorreflexivo), lo hace siempre desde la búsqueda de sí mismo y la recuperación de la memoria personal. Bellour menciona algunos nombres que ejemplifican este trayecto: Jonas Mekas, Chantal Akerman, Raymond Depardon, incluso Welles y Fellini y, por supuesto, Chris Marker.

El movimiento crítico que señala a Marker como autorretratista se ha repetido desde entonces bastante a menudo (Tode, 56; Min Lee, 40). No es sorprendente; tampoco inexacto en sentido alguno. La filmografia de Marker se viene actualizando desde sus primeras películas con base en una escritura del yo, en la que el gesto de tomar la voz adquiere una importancia creciente hasta desembocar en el cd-rom "Inmemory" (1997) donde, según el propio Bellour, "todas las formas del verbo circulan con fluidez (...): yo, tú, él, nosotros, vosotros, ellos, hasta volver al "yo"" (Bellour, El libro 56). En último término no hay duda de que es Marker quien habla en sus filmes y lo hace desde su experiencia como viajero, editor, fotógrafo, amante de los animales o militante de izquierdas en momentos diferentes. Sin embargo, también hay otros elementos que problematizan esta caracterización. El de Marker es siempre un autorretrato velado. Tanto sus películas como su presencia pública están a menudo pobladas por personajes mediadores, que atraen la atención y al mismo tiempo ocultan al autor. De manera más crucial, la fórmula del autorretrato tiende oscurecer aspectos tanto o más importantes en su cine que el acto de decir "yo", e incluso puede llegar a desvirtuar por completo el sentido con el que el cineasta reivindica el uso de la primera persona.

El encuentro con los demás, con su realidad, es también uno de los ejes discursivos del cine de Chris Marker, hasta el punto en el que sus películas no responderían tanto a la pregunta de "¿quién soy?", sino que más bien plantean la cuestión de la construcción de la subjetividad en torno a ciertos encuentros sucesivos. No es el encuentro en sí lo que inscribe el cine de Marker en la esfera de lo personal, ni siquiera la representación de este encuentro en la pantalla, sino más bien el recuerdo subjetivo del mismo y las formas en las que este entra en conflicto con la tendencia de la imagen a objetivizar la experiencia. Es este proceso dialógico el que constituye en gran medida el motor discursivo de sus películas. En la mesa de edición, frente a las imágenes que él mismo ha filmado o frente a otras espigadas de archivos, películas o programas televisivos, Marker parece establecer un diálogo de múltiples capas que abarca a sus personajes, a él mismo y a los discursos que convoca en sus películas. El resultado final es un reflejo del proceso de creación y recreación dialógica que teje al propio Marker, trayendo a la memoria las palabras de Godard según las cuales los 
cineastas que siguen esta fórmula "trabajan todo el rato y nunca acaban una película. $\mathrm{La}$ película se acaba sola" (citado en Zunzunegui, 165).

Por tanto, entender la importancia del otro en Marker implica necesariamente concebir la subjetividad en función del encuentro con los demás. Como explica Catherine Lupton, este acercamiento a la otredad implica

imaginar otro Chris Marker, cuyo trabajo se ilumina precisamente gracias al encuentro con sus semejantes, siendo estos últimos sujetos plenamente autónomos. No se trata pues de buscar continuamente espejos fractales que, en último término, reflejarían una versión más del propio Marker (Lupton, 74. Mi traducción).

La reflexión inicial de Bellour también plantea de forma menos evidente otro de los temas recurrentes en la filmografia de Marker: la inquietud por las formas en las que la mediación tecnológica y estética nos acerca y aleja simultáneamente de la realidad de los demás. Es el video como herramienta de expresión artística el que, según Bellour, brinda posibilidades expresivas concretas que se traducen en un movimiento hacia fórmulas autobiográficas en las últimas décadas del pasado siglo. La cámara, fotográfica o filmica, la mesa de edición, los efectos digitales o de sonido que con tanta frecuencia aparecen en las películas de Marker adquieren su dimensión en relación con el proceso de construcción dialógica que hemos mencionado anteriormente. Más que a la posibilidad de condensar en la imagen la esencia de una realidad pasada (el cáliz documental, el ansiado realismo de grado cero), la autorreflexividad se articula en torno al punto de tensión que le permite representar en sus películas una subjetividad dialógica en continuo desarrollo. El discurso mediado no es aquí testimonio, sino que ya ha sido internalizado como memoria e ilumina las formas en las que la experiencia ajena construyen el yo.

El principal objetivo de este artículo es precisamente el de profundizar en esta lectura dialógica de la subjetividad en el cine de Chris Marker en torno a tres ejes concretos: la construcción de personajes, el papel de la tecnología y la presencia autoral en sus películas. Para ello nos centraremos en Level Five (1998) como el caso de estudio en el que las tres líneas de análisis mencionadas permiten una lectura más fértil. De manera excepcional entre las películas de Marker, Level Five está protagonizada por un personaje de ficción, Laura, quien trata de superar la pérdida de su amante mediante el juego de ordenador que este ha dejado incompleto. El juego gira en torno a la batalla de Okinawa y Laura se verá obligada a revivir las atrocidades cometidas en esta pequeña isla japonesa mientras afronta un duelo personal que acabará con su desaparición, literal, de la narrativa. Su historia la cuenta Chris, editor y amigo de Laura, a quien escuchamos, pero nunca llegamos a ver. Es su voz quien le confirma como el responsable último de la narrativa de Level Five.

La película ofrece una mirada primigenia acerca de lo que hemos dado en llamar "imagen-red" como fórmula desde la que abordar el desplazamiento del centro de gravedad del audiovisual hacia una práctica regida por el principio del intercambio y 
por la omnipresencia de la propia mediación tecnológica. A pesar de ello, y más de quince años después de su estreno, Level Five aún no ha recibido la atención crítica que merece, especialmente en el entorno académico de habla hispana. De ahí también la concepción de este artículo como ejercicio arqueológico, que plantea la recuperación de una pieza no solo valiosa en sí misma, sino tremendamente útil de cara a contextualizar correctamente la actual cultura audiovisual digital.

El segundo de los puntos de anclaje del texto viene dado por el marco teórico de análisis y por la utilización instrumental de varios conceptos tomados tanto de la teoría dialógica del lenguaje concebida por Mijail Bajtín como de sus posteriores reformulaciones en campos tan variados como la psicología (Hermans y HermansKonopka; Hermans y Gieser) o los mismos estudios cinematográficos (Stam; Flanagan,). $\mathrm{Al}$ igual que con el filme escogido, también existe aquí un cierto afán reivindicativo, que defiende la relevancia de ciertos aspectos del corpus teórico definido por el pensador ruso y sus herederos a la hora de analizar los patrones de subjetividad que se articulan en torno a la imagen-red.

De esta forma, el análisis propuesto de los procesos mediados de construcción de la subjetividad que tienen lugar en Level Five privilegia el momento del encuentro con el otro, examinando el tono que el devenir ideológico adquiere en el propio Marker como autor y en cada uno de los personajes del filme. La conclusión apunta hacia la presencia de un principio de exploración dialógica de la realidad como elemento definitorio de la imagen-red; un espacio que, desde la perspectiva temporal de 1997, aparece al tiempo amenazante y pleno de posibilidades en el que late la transformación radical de las formas en las que nos relacionamos con los demás y con la propia realidad.

\section{EL DIALOGISMO COMO PRINCIPIO DE CONSTRUCCIÓN DE LA SUBJETIVIDAD}

La ventaja más importante a la hora de utilizar la teoría dialógica consiste en que ofrece herramientas para estudiar la presencia de la realidad ajena en el ámbito del sujeto, el choque de voces internalizadas que en definitiva constituye la subjetividad. Un acercamiento dialógico a la subjetividad se centra por lo tanto en este conflicto de voces y en las formas en las que el sujeto las asimila, reacentúa, matiza o rechaza. Los hilos del diálogo interior representan diferentes posiciones socioideológicas latentes hasta en las unidades mínimas del discurso. Para Bajtín la subjetividad se articula precisamente en torno a estos procesos de interacción históricamente situados y emprendidos por actores sociales, lo que (a diferencia de las concepciones lingüísticas más clásicas) permite rescatar la comunicación como un fenómeno ideológico en sí mismo. Por ello, Bajtín prefiere hablar de la "translingüística" como disciplina del contexto, firmemente arraigada en la experiencia de quienes comparten un idioma.

El trabajo de Robert Stam supone una contribución clave para comprender conceptualmente la trasposición de los principios discursivos definidos por Bajtín al ámbito del cine y la comunicación audiovisual. Una lectura dialógica de la imagen se sitúa más allá de cualquier noción esencialista, la aborda como discurso visual que 
responde a unos principios ideológicos formulados con intenciones concretas, como "el reflejo de un reflejo, la versión mediada de un mundo socioideológico ya textualizado de antemano" (Stam, 50. Mi traducción). Si consideramos que el trabajo de Marker gira precisamente en torno al gesto de releer la imagen en el tiempo, resulta lógico concluir que los patrones de subjetividad autoral en su obra se definen en gran medida a partir de este roce con la imagen. Buscar a Marker en sus películas implica atender a las formas en las que asimila o contesta las imágenes que componen el filme, poniéndolas en relación con otros discursos y haciéndolas resonar de formas diferentes.

Frente a una concepción documental que acepta la imagen de no ficción como índice, una perspectiva dialógica se asienta en la lectura de la imagen como discurso acerca de la realidad; lo que podemos conocer de ella se encuentra necesariamente enredado en una urdimbre de intenciones, convenciones culturales, entonaciones, etc. En varios pasajes de Problemas de la poética de Dostoievsky, el propio Bajtín alude a los sistemas de conocimiento como la ciencia principalmente como reticentes a la incorporación de una actitud dialógica, ya que tienden a transformar "dinámicas de diálogo abierto en afirmaciones monológicas, resumiendo su contenido pero sin reflejar el espíritu no conclusivo de la realidad" (Bajtin, en Morson y Emerson, 60. Mi traducción). A esto, Bajtín opone la concepción del conocimiento que se materializa en los Diálogos de Sócrates en los que "la verdad no nace o se encuentra en la cabeza de un individuo, sino que se genera entre personas que la buscan de forma colectiva, nace de un proceso de interacción dialógica" (Bajtín, 110, mi traducción). Como veremos en la última sección de este artículo, es este tipo de acercamiento el que determina la posición de Marker en el ámbito del cine de no ficción y su alejamiento de los principios canónicos del documental.

Otro de los puntos sólidos de un acercamiento teórico basado en el dialogismo consiste en la posibilidad de analizar con detalle las relaciones entre el autor y los personajes del relato, sin asumir automáticamente que estos son meramente un trasunto disfrazado de la subjetividad creadora. Bajtín aborda el tema distinguiendo entre el autor y el héroe, término que designa genéricamente a distintos personajes. Al adoptar una postura dialógica, el autor enfoca a sus personajes hacia "una conciencia que tiene un valor similar a la suya, que resulta tan ilimitada e imposible de finalizar como su propia subjetividad" (Problems, 68. Mi traducción). Esto es así incluso en el caso de personajes cercanos al autor, ya que " $m i$ 'yo' no puede identificarse plenamente con el 'yo' que se transforma en discurso. Sería tan imposible como levantar tu propio peso tirándote del pelo" (Bajtín, citado en Todorov, 52. Mi traducción). Esto implica la concepción de la autoría como un espacio suficientemente abierto como para albergar "la conciencia autónoma y plenamente desarrollada que emana de otros discursos" (Bajtín, Problems, 68. Mi traducción).

El concepto que de forma más clara nos permite analizar los rasgos de este intercambio dialógico entre Marker como autor, sus personajes y los discursos e imágenes que componen el filme es el de "devenir ideológico". Según Bajtín, el 
concepto aborda la construcción de la subjetividad como flujo en transformación, que se genera y se redefine en una constante tensión productiva con los demás, como un tapiz tejido a partir de otras voces; “(...) lo que nos pertenece es una forma concreta de orquestar las voces de los otros y el carácter complejo y muy específico del discurso en nuestro interior (...) Nuestro yo no es una voz particular, sino una forma particular las muchas voces que nos habitan" (Morson y Emerson, 221. Mi traducción). Bajtín distingue entre discursos autoritativos e internamente persuasivos. Mientras que los primeros rechazan la relación dialógica (discursos religiosos, por ejemplo, cuya autoridad no permite la interacción y llegan al sujeto como un bloque), los discursos internamente persuasivos permiten diferentes posibilidades de negociación (Bajtín, The Dialogic, 345, 346).

A nosotros nos correspondería pues contrastar dichas voces, relacionarlas, refutarlas y reacentuarlas de forma fructífera de cara a construirnos como subjetividad dialógica en devenir. Mediante este proceso de reacentuación transformamos el significado y lo asimilamos a nuestra propia experiencia, historia y necesidades. La reacentuación supone el punto de encuentro entre el material ajeno y nuestra propia forma de orquestar los discursos. El recorrido de este concepto es tremendamente amplio, ya que no apunta exclusivamente al desarrollo de ideas aisladas, sino que se aproxima a un sentido más general y apunta a una estructura ideológica que se traduce en un sentido de identidad abierta y cambiante (Warshauer-Freedman y Ball).

\section{GAME OVER}

Sentada de forma perenne frente a la pantalla del ordenador, en Level Five Laura se enfrenta al videojuego de la batalla de Okinawa que su pareja recientemente desaparecida ha dejado sin terminar. Desde el comienzo de la película, el espectador observa su creciente fijación por este videojuego y por el episodio histórico que recrea. Laura comienza a jugar de forma casi ritual, a modo de duelo por su pareja; sin embargo, mediante el propio juego, empieza a indagar acerca de lo que ocurrió en Okinawa mediante testimonios, libros, trozos de película, boletines de radio o recortes de periódico. Poco a poco irá complementando esta información por fuentes externas, sobre todo gracias a la OWL (Optional World Link) donde también encuentra todo tipo de variopintos personajes con los que interactuar. Laura comparte sus recuerdos con una cámara fija situada frente a ella, sobre la pantalla del ordenador. Aunque se trata de un personaje profundamente cinematográfico (su nombre es un homenaje a la película homónima de Otto Preminger), su búsqueda se ve lanzada por la imagen-red, en un gesto que recuerda la mirada del ángel de la historia de Benjamin. De hecho, la fórmula elegida por Marker para conectar al espectador con Laura anticipa el formato confesional del video-blog que portales como YouTube popularizarían muchos años más tarde. 


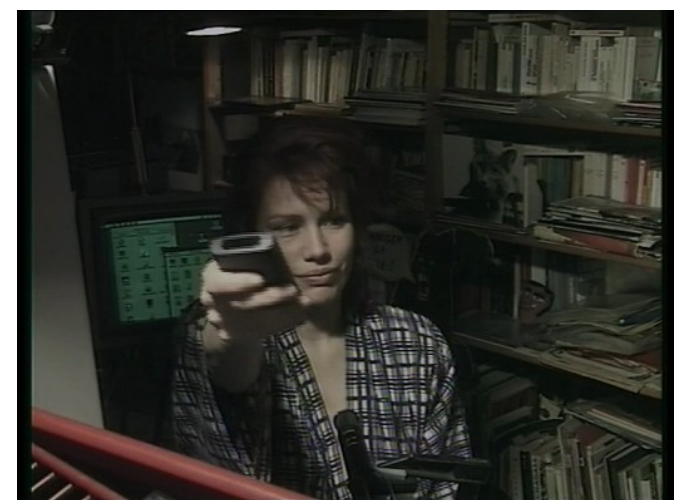

Figura 1. Laura ajusta su propia imagen en la pantalla (Level Five, Chris Marker, 1998)

En línea con la visión bajtiniana de la subjetividad, Laura aparece en Level Five como alguien que "se constituye y cambia continuamente a través de un proceso interminable de interacción sociolingüística" (citado en Pearce, 89. Mi traducción) que, en este caso, se hace posible gracias a la mediación de la red, ya que ella en ningún momento del filme aparece junto con otro personaje. Por medio de sus monólogos, el espectador accede a la materialización de su discurso interior, en el que es posible ir adivinando a medida que avanza la película el efecto que la tragedia de Okinawa va teniendo sobre Laura. Su intento inicial de jugar el juego creado por su pareja parece responder de forma exclusiva a un deseo personal de aferrarse a ella, de mantener algún tipo de relación con alguien que ya ha desaparecido y a cuyo alejamiento definitivo Laura se resiste hasta el final de la película. Sin embargo, el personaje parece evolucionar desde esta posición egocéntrica a lo que podríamos denominar como un estado de empatía extrema con el dolor de las víctimas.

La imagen que devuelve el videojuego recrea la batalla de Okinawa con el aire autoritativo del discurso histórico, lo que cierra cualquier posible vía de interacción, impidiendo a Laura tanto escapar al horror como reacentuarlo. En su artículo "Visual Forms of Representation and Simulation: A Study of Chris Marker's Level Five", Yvonne Spielmann distingue de forma explícita entre las estructuras analógicas y digitales presentes en el filme. Mientras que los medios cinemáticos y electrónicos (cine $\mathrm{y}$ video) se basan en el principio de representación y dependen de la captura de la realidad física, argumenta Spielmann, las imágenes digitales responderían mejor a la idea de simulación, debido a que "no se considera que respondan a la idea de factualidad (...) según un principio de contigüidad con la realidad" (Spielmann, 20. Mi traducción). Resulta evidente que en Level Five la intención inicial de Laura consiste en jugar al videojuego, intentando cambiar el curso de la batalla en cada partida. Sin embargo, el programa se niega a alterar el desarrollo de la historia, repitiendo una y otra vez el sentido de los eventos tal y como ocurrieron en el pasado. Es este bucle y la imposibilidad de poner en marcha un principio de simulación completo lo que fuerza a Laura a conocer la tragedia real de Okinawa. En lugar de un software que permite al 
usuario reinventar la narrativa histórica y burlar metafóricamente la certeza de la muerte, el juego se transforma en una metáfora de la certeza de ambos fenómenos.

Laura también se muestra incapaz de reacentuar los discursos del horror que la van tejiendo a lo largo de la película. Cuando habla de la "mujer-pantalla" en $L a$ muchacha de los ojos de oro de Balzac la metáfora parece hecha para ella misma: un rostro sobre el que se acaban condensando las tragedias del siglo singularizadas en la historia de esta pequeña isla de Pacífico. De hecho la imagen gráfica que mejor define a Laura es la aparición en varias ocasiones de una cabeza de plástico blanca, de aire vagamente femenino sobre la que en diferentes momentos se proyectan las imágenes de la propia película. El rostro femenino, que tan a menudo se asocia en la filmografía de Chris Marker con la humanidad y la individualidad, aparece aquí como un lienzo sin pintar, que se limita a reflejar imágenes distintas hasta acabar con la desaparición de la propia Laura, convertida ella finalmente en otra imagen más.

Otra de las vías de escape que ofrece la imagen-red se escenifican en los intercambios con la OWL. A medida que avanza la película, Laura acabará utilizando la OWL para enmascarar su dolor y convertirse, aunque sea de forma temporal, en otra persona. De hecho, la condición necesaria de acceso a la OWL es utilizar una máscara. "Pick your mask" (Escoge tu máscara), leemos en las pantallas de acceso. A diferencia de su interacción con el juego, en el que un sistema de identificación permite o deniega el acceso al jugador, la OWL parece abierta a todo el mundo, aunque su acceso requiere el anonimato y el pseudónimo. La actividad dialógica de Laura en la OWL siempre está marcada por la confusión, la simulación y el engaño. El supuesto famoso que trata de convencerla acerca de que va a suicidarse o bien miente o simula ser alguien que no es. De la misma forma, un desconocido pregunta a Laura en varias ocasiones si ella es "su bebe burrito" y a menudo la propia Laura cree haber encontrado a su pareja fallecida entre las máscaras de la OWL.

En un primer momento, las interacciones de Laura en la OWL parecen destinadas a obtener información sobre Okinawa; sin embargo, los resultados son siempre sorprendentes. En su primer acceso registrado, la OWL parece una inmensa base de datos multimedia. Se trata de una impresión que confirma la sucesión de imágenes que ilustran esta primera entrada: el logo de la revista Time, imágenes de archivo de la Segunda Guerra Mundial, una esvástica. No nos encontramos aquí con el camino cerrado que caracteriza al juego, sino con un ecosistema dialógico abierto, que configura una forma distinta de investigación y conocimiento. Sin embargo, la visión de la película sobre la OWL también parece contener un mensaje acerca de los peligros de separar dicho proceso de un base identitaria clara. Dichas advertencias se materializan en la última entrada de Laura en la OWL, cuando se ve obligada a enfrentarse con ella misma cuando encuentra su propio rostro detrás de una de las máscaras con las que interactúa.

La desaparición final de Laura en la narrativa está en sintonía con una de las posibilidades extremas que apunta Bajtín como ejes en nuestra relación con los demás: "la pérdida de criterio y, en última instancia, la absorción del otro, hasta el extremo de la 
confusión entre nuestras propias palabras y las del otro" (citado en Stam, 217. Mi traducción). Bajtín aun es más explícito en su ensayo Hacia una filosofia del acto ético, a la hora de abordar el concepto de empatía.

Después del momento de empatía siempre sigue el de objetivación, es decir, el situar la individualidad aprehendida mediante la empatía fuera de uno mismo, y solo esta conciencia que retorna a sí misma, desde su lugar confiere una forma estética a la individualidad aprehendida mediante la empatía desde el interior, como a una entidad singular, íntegra y cualitativamente peculiar (22, mi traducción).

Es precisamente la imposibilidad de realizar este movimiento de objetivación, de separarse de los discursos del horror, el que lleva a Laura a internalizarlos sin posibilidad de reacentuarlos, hasta el punto de que no puede distinguir su propio dolor dentro de la herida general de la historia.

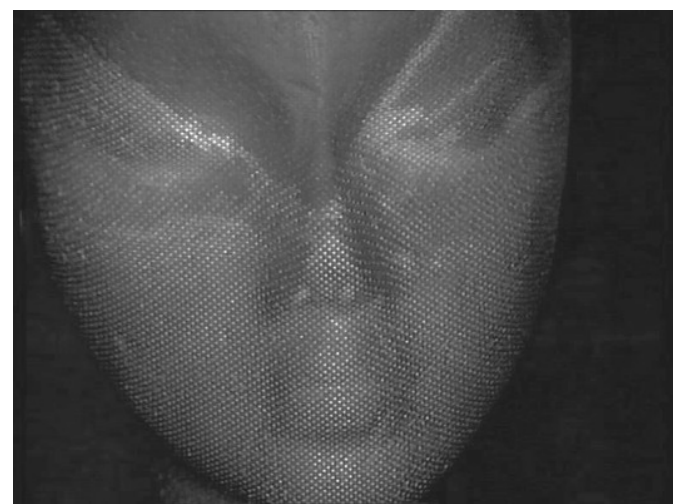

Figura 2. El rostro como pantalla (Level Five, Chris Marker, 1998)

\section{HISTORIA Y MEMORIA}

En Level Five, Marker accede a deshacerse de algunas de sus máscaras cinematográficas más habituales para construir un personaje, también llamado Chris, más cercano a sus hábitos de trabajo. Es admisible señalar que el escenario en el que se filma la mayor parte de la película es, de hecho, el taller de trabajo del propio Marker; aparecen sus libros, imágenes de sus gatos, sus ordenadores o su mesa de montaje (Alter, 111). En ningún momento vemos a Chris, sin embargo, es el propio Marker quien presta su voz al personaje (Bellour, Chris Marker). Es precisamente Chris quien asume el reto de acercarse al dolor de Laura y a la tragedia de Okinawa para configurar un espacio autoral dentro de la narrativa, lo que en último término dirige de nuevo el discurso hacia la actividad del propio Marker y hacia su trabajo con las imágenes.

A diferencia de Laura, Chris parece rehuir el encuentro directo con Okinawa desde una lógica histórica. En su primera intervención se apresura a explicar que ha comenzado a compartir la amnesia japonesa que envuelve todo lo relacionado con la 
Segunda Guerra Mundial para, a partir de este momento, abordar la tragedia desde el punto de fuga de la memoria, una perspectiva mucho más centrada en aspectos como el recuerdo reprimido, el desarraigo cultural nipón o las políticas de la memoria en el Japón de principios y mediados de los noventa. En la narrativa, esta perspectiva se traduce en la visita a museos, centros turísticos y comerciales, mercados y lugares de socialización tanto en Tokio como en la propia Okinawa; unas imágenes en las que sobrevuela la pregunta de quién y cómo se recuerda la tragedia. Se trata de un movimiento significativo, ya que permite a Chris desactivar la autoridad del discurso histórico y transformarlo en un discurso internamente persuasivo, abierto a la negociación. Si bien uno no puede simular que no ocurrió lo que ocurrió, sí es posible negociar qué se recuerda, cómo y con qué sentido.

A modo de ejemplo, podemos considerar la visita al mercado de Naha, en Okinawa, y en particular la estrategia de montaje escogida por Chris para acercarse a este espacio vivo, "dirigido por mujeres; todas ellas vinculadas a la guerra: viudas o huérfanas, algunas supervivientes" (Marker, Level Five). En primer lugar el filme muestra unas cuantas imágenes cotidianas, tenderas de edad ocupadas en sus puestos, clientas ancianas con niños, que pasean entre frutas, verduras y otros productos. Toda la escena dura menos de un minuto, antes de regresar a un recorrido turístico que nos lleva a conocer el popular monumento a las enfermeras de Himeyuri-no-to, estudiantes de enfermería movilizadas por el ejército nipón muchas de las cuales acabaron perdiendo la vida en el frente o suicidándose con granadas de mano antes que caer en manos del enemigo. Es este el momento en el que, sobre imágenes del interior de las cuevas en las que se escondían estas muchachas junto con los heridos del frente, Chris confronta el horror de lo sucedido:

Para comprender lo que pasó en Okinawa uno debería descender a las cuevas con una cuerda y una linterna. Una vez abajo, hay que apagar la linterna e imaginar a una adolescente, sola en la oscuridad, rodeada de cadáveres que se descomponen, amputaciones sin anestesia, el sonido de los gusanos entre la carne viva y otros sonidos: los gritos de los agonizantes, la imploración hambrienta para que se cocinen los miembros amputados. Hay que tratar de imaginarse eso, y también la más que probable solución: los lanzallamas.

Solo después de este giro en la narrativa, Chris regresa al mercado y a los rostros de las ancianas para afirmar que, algún día, estará compuesto solo por comerciantes como los de cualquier otro mercado, pero que mientras estas mujeres sigan aquí, este es el lugar donde se encuentra la memoria de Okinawa. Frente a un discurso que coloca en primer plano la amnesia generalizada y transforma la tragedia en espacio de atracción turística, Chris opone una memoria humana, que permanece en el ámbito de lo íntimo. En pocas palabras, su discurso en la mesa de montaje reacciona frente a lo que ve y hace suya una respuesta oposicional, que denuncia una política de la memoria que comercializa la tragedia y la convierte en espectáculo. 


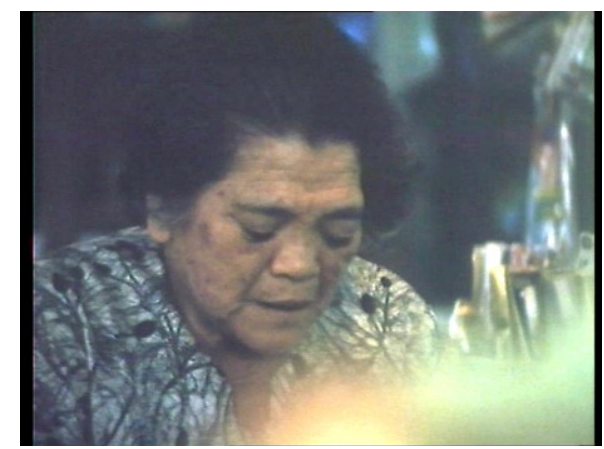

Figura 3. Guardianas de la memoria en el mercado de Naha (Level Five, Chris Marker, 1998)

De igual forma, el tono del montaje y de las intervenciones de Chris también difiere profundamente de las alocuciones a la cámara por parte de Laura. Para caracterizarlo podríamos utilizar aquí lo que Ursula Le Guin denomina como lengua nativa, en cuanto combina reflexiones de corte sociológico, filosófico e histórico con un tono que no deja de lado la empatía con las víctimas y los testigos. Todo ello sin caer en la equidistancia ni en la ilusión de la objetividad. Esta lengua nativa nace del encuentro de las lenguas paterna y materna. La lengua paterna, explica Le Guin, se articula en el lenguaje de las instituciones, de la ciencia y la política, comparable a la "voz de Dios" de los documentales clásicos. Por otro lado, la lengua materna es el idioma de las historias, de la fantasía y de la rutina diaria: el registro lingüístico que adoptan las madres frente a sus hijos y que, a ojos de la lengua paterna, aparece como poco claro, trivial y cargado de banalidad. En último plano la lengua nativa destila el encuentro del sujeto y el objeto, dando lugar a lo que Le Guin define como:

el matrimonio del discurso público y la experiencia privada, dando lugar a un espacio de razón auténtico. Se trata del enlace, la separación y el refuselaje de la consciencia alienada de la lengua paterna y del compromiso indiferenciado de la lengua madre (citado en Dermody, 301. Mi traducción).

Así, la afirmación de la subjetividad de Chris mediante la lengua nativa se contrapone de forma evidente a la caída de Laura en el idioma materno como reacción que acaba dando como resultado la empatía indiferenciada de la que hablábamos anteriormente.

Estos tonos distintos resultan aún más evidentes en las raras ocasiones en las que ni Chris ni Laura se encuentran en control directo del discurso de Level Five. En un momento del filme, Laura fantasea con la idea de que un etnógrafo del futuro encuentre sus mensajes en video y los utilice para extraer conclusiones acerca de los ritos funerarios de la gente del siglo XX. Es una idea que de inmediato provoca el tipo de discurso que Le Guin asocia con el lenguaje materno: en este caso, Laura imagina que el etnógrafo se enamora de ella. Poco después de esta escena aparecerá una voz 
masculina, mecánica y distorsionada que, en tonos futuristas, reflexiona respecto del significado del ciberespacio:

El conocimiento como valor. La fiabilidad del conocimiento que circulaba por la web era cuestionable, claro que de eso iba el juego: conseguir que la información circulase cada vez más deprisa. En el pasado, para dotar al dinero de la importancia necesaria habían recurido a un material denso, raro, que funcionase de la misma forma que una promesa dentro de un cofre. Eligieron el oro. A medida que el dinero se volvió invisible y volátil, los nuevos poderes necesitaron un juramento igualmente volátil e invisible. Eligieron el conocimiento (Marker, Level Five).

El tono de esta voz nos remite de nuevo a un discurso autoritativo cuya autoridad (muy al estilo de Marker) corresponde a un pasado que es en realidad el futuro. La aparición de esta voz indiferente y mecánica contiene igualmente una referencia directa al thriller futurista de Jean-Luc Godard, Alphaville (1965) en la que un científico totalitario gobierna la ciudad de Alphaville mediante una computadora que ha prohibido cualquier forma de amor o expresión de la subjetividad en aras de la lógica. Aquí, a pesar de que se trata de una reflexión provocativa, profunda e interesante, la falta de empatía con el otro resulta evidente y se enfatiza mediante el uso de la tercera persona del plural.

\section{REACENTUACIÓN DEL DOCUMENTAL}

Dos de los aspectos teóricos que ya hemos examinado en este análisis de Level Five (la ruptura con el lenguaje paterno y el énfasis puesto en la imagen como discurso) también determinan el rechazo expreso que contiene la película de los formatos documentales clásicos y que explicita la posición de Marker como autor en el ámbito de la no ficción. Definidos originalmente por las ideas de John Grierson en la década de los treinta, y por el paradigma de la separación objetiva que caracteriza los formatos observacionales, el documental como género se ha relacionado de forma histórica con un acercamiento pseudocientífico a la realidad, en un intento de mostrar la vida "tal y como es". Incluso hoy, la palabra documental invoca nociones como equilibrio, imparcialidad y veracidad que a menudo se asocian con la autoridad del ámbito científico y su naturaleza sistemática. Bill Nichols explicita este vínculo cuando incluye la práctica documental en cine entre los que denomina como "discursos de sobriedad".

Ciencia, economía, política, relaciones internacionales, educación, religión, bienestar, estos sistemas asumen un cierto poder instrumental; pueden y deben alterar el mundo; pueden poner en efecto acciones y generar consecuencias. El discurso que les es propio tiene un aire de sobriedad que les aleja de los personajes de ficción, de los hechos o los mundos imaginados (...). Los discursos de sobriedad son austeros porque perciben su relación con el ámbito de lo real como directa, inmediata, transparente (Nichols, 3-4. Mi traducción).

La referencia a personajes, hechos y mundos de ficción está destinada a reafirmar la especificidad del ámbito documental, mientras que la mención a una 
relación con lo real "directa, inmediata y transparente" conscientemente borra cualquier resto de subjetividad, duda y tentatividad. La aspiración a una representación cuasicientífica de la realidad en el documental cierra el discurso al ámbito de la interacción dialógica y demanda un reconocimiento de la autoridad de la forma.

Es posible observar el rechazo de Level Five a esta ética documental basada en la sobriedad en la definición que el propio Marker hace del filme como un "semidocumental". En las notas que acompañaron al estreno de Level Five, Marker explicaba el término refiriéndose a las palabras del magnate cinematográfico Harry Cohn en las que hablaba del documental como "un film sin personaje femenino. Cuando aparece un personaje femenino, estamos ante un film semidocumental" (citado en Blümlinger, 42). Como es habitual, la broma de Marker esconde un subtexto al que conviene prestar atención y que apunta directamente a la imposibilidad de encontrar en los documentales elementos como el deseo, la emoción, la compasión o la duda (asociados burdamente por Cohn con los personajes femeninos).

El rechazo de esta idea de documental resulta aún más explícita en la narrativa cuando, cerca del final de Level Five, Laura habla acerca de Gustave: un soldado en llamas cuyas imágenes han recorrido todo tipo de documentales desde el final de la Segunda Guerra Mundial. Sin embargo, explica Laura, en las imágenes originales (cortadas en la mayor parte de películas en las que aparecía Gustave) es posible ver que Gustave logra apagar sus llamas y no muere: la idea es que logrará recuperarse. El ejemplo provoca una airada reacción contra la idea de la verdad documental verbalizada por Laura, en la que se enfatiza que la verdad incuestionable que muchos documentales parecen dar por establecida es, en realidad, siempre la verdad de alguien.

Gustave testifica contra la guerra. No es posible debilitar su testimonio solo para incluir unos segundos más de metraje. ¿La verdad? ¿Qué es la verdad? La verdad es que la mayoría no se levanta. ¿Por qué darle a este un tratamiento especial? ¿La ética de la imagen? ¿Es ético el Napalm? ¿Estás a favor del Napalm? ¿En qué lado estás camarada? (Marker, Level Five)

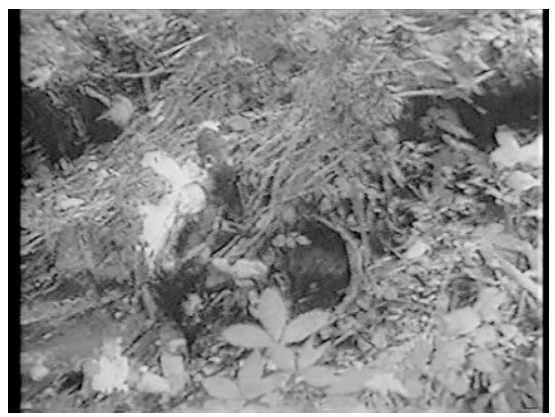

Figura 4. Gustave o el sufrimiento como discurso (Level Five, Chris Marker, 1998) 
El contrapunto al episodio de Gustave lo pone en el filme la historia de Ira Hayes, un marine que tomó parte en lo que el filme define como la escenificación para la cámara del levantamiento de la bandera americana en Iwo Jima en 1945, que resultó en la famosa fotografia de Joe Rosenthal en la que seis marines norteamericanos izan la bandera estadounidense en la cima del monte Suribachi. Laura explica que, de condición sencilla, Hayes nunca superó haber tomado parte en una mentira para favorecer a su bando y acabó con problemas de alcoholismo y muriendo en la indigencia ${ }^{1}$. Mediante la contraposición de estos dos episodios, Marker parece apuntar hacia su propia posición dentro del ámbito del cine de no ficción, reafirmando que, a la hora de tratar con el dolor de los demás, uno no solo tiene la responsabilidad moral de tomar la palabra y explicar su posición, sino que también debe explicar por qué hace lo que hace, explicando sus decisiones y compartiéndolas con el espectador para que este pueda posicionarse al respecto.

En Level Five esta problematización de la transparencia determina un acercamiento al conocimiento que, en lugar de separarse de la realidad retratada, pone en juego sentimientos de empatía y solidaridad. Es una consecuencia natural de la posición de Marker como autor. En lugar de centrarse en lo que ocurrió, se busca favorecer la presencia de múltiples perspectivas relativas a los hechos, desde la visión de la historia como una realidad mediada por las experiencias personales, el recuerdo, la tecnología, etc. La única respuesta posible en este entorno, parece decir Marker, es un diálogo que parta del reconocimiento de intenciones opuestas sin renunciar a la interacción entre ellas.

\section{CONCLUSIONES}

La riqueza metafórica de Level Five sugiere innumerables lecturas. La película puede interpretarse por ejemplo desde la perspectiva histórica y de recuperación de la memoria, como una reflexión acerca del horror del siglo XX. Desde esta perspectiva, resulta tentador concebir el filme como la radiografia de un único encuentro: el del espectador con la memoria del pastor cristiano Kinjo Shigeaki. Ante la inminente derrota del ejército nipón en la batalla de Okinawa, y siendo tan solo un adolescente, Kinjo mató a su madre y a su hermana imbuido de la ética samurai y del miedo al enemigo que transmitía la propaganda imperialista japonesa. Creyó estar ayudándoles. La historia es real y puede contarse; a veces tan solo en un par de frases, como acabamos de hacer. Sin embargo, el problema que plantea Level Five no apunta únicamente a los hechos, sino a cómo situar al espectador para que se produzca este encuentro, cómo orientarle hasta el lugar desde el que sea posible el acercamiento de dos subjetividades distantes mediante la imagen. En sus mejores momentos, como

\footnotetext{
${ }^{1}$ Han habido interpretaciones distintas y encontradas acerca de esta fotografia. Su autor, Joe Rosenthal, ha defendido en diferentes ocasiones que la fotografía no es un montaje y que todo fue una confusión. Para una discusión en profundidad de este tema ver Thomey, 2008.
} 
deja entrever la película, el buen cine no sería más que esto: acercarse con respeto a la realidad de los demás. Cómo filmar al otro, hasta qué punto implicarse en su historia o de qué forma la tecnología nos sitúa frente a la existencia de nuestros semejantes son las cuestiones que más claramente estructuran Level Five y que resuenan con un profundo eco en la filmografía del cineasta francés. En este sentido, es posible concebir el filme como una película de cierre, de despedida de un medio, el cinematográfico, con el que Marker había recorrido buena parte del siglo XX y que ahora muere con él. Si acaso la filmografía de Marker permite analizar diferentes estadios de este pasaje de la imagen desde, al menos, la utilización de distorsionadores en la banda sonora de Junkopia (1981) o las imágenes solarizadas de Sans soleil (1982).

La imagen-red que Marker retrata en Level Five se configura, en primer lugar, como objetivización y simulación de los procesos de la memoria. La incapacidad de Laura para simular una nueva batalla de Okinawa en el juego incompleto de su amante pone de relieve en el contexto del filme un sentido de desarraigo identitario asociado a la tecnología de la imagen-red. En relación con los medios tradicionales, Internet permite activar el uso y la negociación constante de posiciones subjetivas, lo que hace necesario replantearse la cuestión de la subjetividad desde un punto de partida discursivo. Los usuarios de las redes interactúan en formas diversas, construyendo identidades efímeras mediante elementos culturales como textos, videos, canciones o fotografías, entre otros. Esto requiere de herramientas analíticas que vinculen la construcción de identidades al proceso de intercambio discursivo continuo que propone la lógica de la red.

A partir del análisis dialógico de Level Five, el presente artículo ha buscado desenterrar un principio ético y estético clave dentro de la filmografía de Chris Marker: el papel del otro en la configuración de la subjetividad personal. Como explicábamos en la introducción, este ejercicio analítico se ha llevado a cabo atendiendo a la construcción de personajes, al papel de la tecnología y a la presencia autoral en el filme. Los personajes de Level Five se configuran en torno a una serie sucesiva de interacciones mediadas que determinan su devenir ideológico a lo largo del filme, es decir, se definen en la fricción dialógica con diferentes discursos, personas, historias, etcétera. Nuestro análisis ha hecho igualmente hincapié en el concepto de reacentuación como eje de la capacidad para generar una lectura propia y productiva del ecosistema dialógico frente al que se define la subjetividad. Aquí, mientras Laura se muestra incapaz de reacentuar la tragedia de Okinawa, Chris desactiva la autoridad del discurso histórico no con el objetivo de escapar del mismo, sino con el afán de situarlo en el plano intersubjetivo para, desde ahí, plantear posibles respuestas al dolor del siglo. La lectura dialógica propuesta termina en el terreno de Marker como autor y de su posición en el ámbito del cine de no ficción. Aquí, el texto aborda el rechazo de Marker del documental como principio de representación de la 
realidad frente a la necesidad de situar histórica, económica y políticamente los discursos que han tejido la historia audiovisual del pasado siglo.

\author{
Universidad de Sevilla* \\ Facultad de Comunicación \\ Departamento de Periodismo I \\ Avda. Américo Vespucio, s/n La Cartuja (41092) Sevilla (España) \\ davidmontero@us.es
}

\title{
OBRAS CITADAS
}

Alter, N. Chris Marker. Urbana y Chicago: University of Illinois Press, 2006

Bajtín, M. Hacia una filosofia del acto ético. De los borradores y otros escritos. Barcelona: Anthropos, 2007.

— The Dialogic Imagination. Austin: Austin University Press, 1981.

— Problems of Dostoevsky's Poetics. Minneapolis y Londres: University of Minnesota Press, 1984.

Bellour, R. Entre imágenes: foto, cine, video. Buenos Aires: Colihue, 2009.

__ "El libro, ida y vuelta". En Chris Marker: retorno a la inmemoria del cineasta. Volumen colectivo. Sevilla y Barcelona: Ediciones de la Mirada, 1998.

_ "Chris Marker and Level Five", disponible en http://www.screeningthepast.com /2013/12/chris-marker-and-level-five/, 2013. Traducción de Adrian Martin.

Blümlinger, C. "Lo imaginario de la imagen documental". En Chris Marker: retorno a la inmemoria del cineasta. Volumen colectivo. Sevilla y Barcelona: Ediciones de la Mirada, 1998.

Dermody, S. "The Pressure of the Unconscious upon the Image. The Subjective Voice in Documentary". En Deveraux, L. y Hillman, R. (eds.). Fields of Vision. Essays in Film Studies, Visual Anthropology and Photography. Berkeley: University of California Press, 1995.

Flanagan, M. Bakhtin and the movies. New ways of understanding Hollywood film. Londres: Palgrave Macmillan, 2009.

Freedman, W. y Ball, A. "Ideological becoming: Bakhtinian concepts to guide the study of language, literacy, and learning". En: Bakhtinian perspectives on language, literacy, and learning. Vol. 3. №33 (2004).

Hermans, H.J.M. y Gieser, T. Handbook of Dialogical Self Theory. Cambridge: Cambridge University Press, 2014.

Hermans, H.J.M. y Hermans-Konopka, A. Dialogical Self Theory: Positioning and Counter-Positioning in a Globalizing Society. Cambridge: Cambridge University Press, 2010.

Lupton, Catherine. Chris Marker. Memories of the Future. Londres: Routledge, 2005 
Min, L. "Red Skies. Joining Forces with the Militant Collective SLON". En: Film Comment, July-August. New York, 2003.

Morson, G. S. y Emerson, C. Mikhail Bakhtin. Creation of a Prosaics. Stanford: Stanford University Press, 1990.

Nichols, B. Representing Reality. Issues and Concepts in Documentary. Bloomington and Indianapolis: Indiana University Press, 1991

Pearce, L. Reading Dialogics. London: Edward Arnold, 1994.

Spielmann, Y. "Visual Forms of Representation and Simulation: A Study of Chris Marker's Level 5". En Convergence: The International Journal of Research into New Media. Vol. 6, № 2. Luton (2000).

Stam, R. Subversive Pleasures: Bakhtin, Cultural Criticism and Film. Baltimore: John Hopkins University Press, 1992.

Thomey, T. Immortal Images: A Personal History of Two Photographers and the Flagraising on Iwo Jima. Annapolis: Naval Institute Press, 2008.

Tode, T. "Fantasma Marker. El inventario antes del filme". En: Ortega, M. L., Weinrichter, A. (eds.). Mystère Marker. Pasajes en la obra de Chris Marker. Madrid: T\&B Editores, 2006.

Todorov, T. Mikhail Bakhtin: the dialogical principle. Manchester:Manchester University Press, 1984.

Zunzunegui, S. "El coleccionista y el explorador: A propósito de 'Immemory'. En: Ortega, M. L., Weinrichter, A. (eds.). Mystère Marker. Pasajes en la obra de Chris Marker. Madrid: T\&B Editores, 2006. 